\title{
Cartas de Juan Carlos Onetti para Julio Payró
}

\author{
Letters from Juan Carlos Onetti to Julio Payró \\ Karina de Castilhos Lucena \\ Universidade Federal do Rio Grande do Sul - Porto Alegre - Rio Grande do Sul - Brasil
}

\begin{abstract}
$\diamond$
Resumo: Este artigo analisa as cartas enviadas pelo escritor uruguaio Juan Carlos Onetti (19091994) ao crítico de arte argentino Julio Payró (1899-1971) entre 1937 e 1955. A análise desses documentos contradiz uma faceta generalizante presente na fortuna crítica do autor, que o descreve como homem solitário e frio. Nos textos aqui estudados, Onetti manifesta seu carinho e admiração por Payró. Da mesma forma, as cartas oferecem dados que contestam a imagem do Onetti descompromissado, já que ele demonstra preocupação com os rumos da política de seu país. A correspondência também revela inseguranças e vaidades que a figura pública fazia questão de manter escondidas. Nesse sentido, este trabalho sugere que investigações a partir de documentos pessoais de escritores podem ampliar fortemente a interpretação de sua obra e às vezes se opor a juízos estabelecidos pelos críticos que não tiveram acesso a esse material.
\end{abstract}

Palavras-chave: Juan Carlos Onetti; Cartas; Julio Payró

\begin{abstract}
This article analyses the letters sent by Uruguayan writer Juan Carlos Onetti (19091994) to Argentine art critic Julio Payró (1899-1971) in the period of 1937-1955. The analysis of such documents contradict a generalizing facet present in the author's critical fortune, that describes him as a cold and lonely man. On the texts hereby studied, Onetti demonstrates his affection and admiration for Payró. Likewise, the letters offer data which contest the image of an uncommitted Onetti, since he demonstrates preoccupation with the course of politics in his country. The mail also shows insecurity and vanity which the public figure demanded to maintain hidden. In this sense, this work suggests that investigations coming from writers' personal documents may strongly amplify the interpretation of his work and often oppose to judgements previously made by the critics who did not have access to this material.
\end{abstract}

Keywords: Juan Carlos Onetti; Letters; Julio Payró.

Juan Carlos Onetti consagrou-se como autor de contos, novelas e romances; sua atuação nesses três gêneros o transformou em um dos mais importantes escritores do século XX hispano-americano. Na verdade, o século XX foi o século de ouro dessa literatura: autores, obras e público em uma relação dialeticamente íntegra - para usar os termos de Antonio Candido - foram responsáveis por um movimento que se convencionou chamar o boom da literatura hispano-americana.

Nos anos 1960 e 1970 uma série de escritores nascidos em países americanos muito diferentes entre si chegavam à maturidade literária e eram reconhecidos internacionalmente. Os principais nomes ainda são Gabriel García Márquez, Mario Vargas Llosa e Julio Cortázar. No entanto, o interesse internacional não buscava apenas a literatura. A revolução cubana atraiu os olhos do Velho
Mundo para a América hispânica e as constantes guerras civis e golpes militares que definiram a história da região na segunda metade do século XX foram responsáveis por manter a atenção da Europa nesta parte do Ocidente. Com matéria histórica tão rica, a literatura encontrou campo livre para representar essa realidade que já interessava ao velho continente e conquistar leitores nas mais diversas partes do globo.

Onetti, nascido em 1909, logo de uma geração anterior a dos escritores que se consagraram com o boom, "pegou carona" nesse movimento. Embora parte considerável de sua obra tenha sido publicada antes de 1960, foi a partir dessa década que o uruguaio passou a ser lido e visto como o escritor relevante que de fato é. Essa recepção tardia criou alguns problemas na interpretação da obra onettiana. Erigiu-se como cânone a denominada 
saga de Santa María, composta pelos livros $A$ vida breve (1950), O estaleiro (1961) e Junta-cadáveres (1964), ambientados os três nessa cidade imaginária criada por Onetti. Esses romances, os mais existencialistas do autor, escritos no auge dessa corrente de pensamento, passaram a definir a obra de Onetti como um todo. Assim, os críticos onettianos, em geral também existencialistas, começaram a interpretar a obra anterior e posterior a essa saga - e também a biografia de Onetti - como símbolo do individualismo, do descompromisso com a história, do afastamento da realidade objetiva. É certo que na saga de Santa María Onetti investe na criação de enredos que não respondem a uma condição histórica específica, mas a leitura de sua obra inicial como preparação para um cânone que se estabeleceria nos anos 1960 e de sua obra final como consequência desta é uma simplificação que só empobrece os estudos onettianos.

Os anos iniciais de Onetti são marcados pelo engajamento do escritor em atividades de esquerda, notadamente seu envolvimento na equipe diretiva do semanário Marcha de Montevidéu que se tornou um clássico dessa orientação ideológica. Na primeira metade do século XX, a experiência socialista na URSS, o franquismo na Espanha, o nazismo na Alemanha e depois no Ocidente, com a eclosão da Segunda Guerra Mundial e o reflexo disso na sociedade rio-platense, que também passava por períodos de autoritarismo e censura, são acontecimentos que balizaram a formação social e, por conseguinte, a literatura. E Onetti não virou as costas a esses eventos que se manifestam em sua obra inicial; estão em Avenida de Maio - Diagonal - Avenida de Maio (1933), O poço (1939) e Terra de ninguém (1942), respectivamente, primeiro conto, novela e romance publicados por Onetti, para citar três picos de representação histórica na narrativa onettiana, embora isso seja uma constante nos textos publicados no período.

A partir de 1975, Onetti estabelece residência em Madrid, devido ao exílio que a ditadura militar uruguaia lhe impõe. Inicia-se, então, a fase final de sua narrativa, na qual a temática do exílio estará presente, configurando, assim como nos anos iniciais, um período no qual a matéria histórica está refletida na ficção.

A heterogeneidade da escrita de Onetti não está presente apenas nos gêneros que lhe consagraram. Em textos paraliterários - cartas, artigos para jornal - também se manifesta essa diversidade. Nesse sentido, a análise das cartas pessoais do escritor sugere uma postura diferente daquela tradicionalmente a ele atribuída. Entre 1937 e 1955 - sendo que a maioria das cartas foi escrita antes de 1941 -, Onetti correspondeu-se com o crítico de arte argentino Julio Payró (1899-1971). É provável que a amizade entre os dois tenha sido selada na casa do artista uruguaio Joaquín Torres García (1874-1949), admirado por ambos e uma figura intelectualmente importante no Uruguai das primeiras décadas do século XX. As visitas de Onetti a Torres García são descritas nas cartas e sabe-se que Julio Payró, educado na Europa, volta ao Uruguai em 1927 para estudar com seu antigo mestre, já que Torres havia sido seu professor em Barcelona.

A correspondência de Onetti a Payró foi encontrada pelo crítico Hugo Verani nos arquivos da Universidade de Notre Dame e do Getty Research Institute, ambos norteamericanos, e publicada em livro em 2009. A edição e fixação dos textos contribui para a recente mudança na recepção dos escritos de Onetti, na qual se pleiteia um autor mais heterogêneo do que costumeiramente aparece retratado. A análise das cartas alude a um Onetti sentimental, buscando a aprovação do já conceituado crítico, ao mesmo tempo em que se mostra muito seguro e confiante em uma obra até então composta por meia dúzia de contos trabalhosamente publicados.

\section{Um homem sentimental}

É comum que ao estabelecermos relações de amizade, deixemos transparecer uma imagem diferente daquela que sustentamos publicamente. Juan Carlos Onetti não foge a essa regra e a correspondência com Payró dá mostras disso. Por exemplo, nos vocativos iniciais das cartas: "Querido Payró" (2009, p. 35), "Querido Julio" (2009, p. 55), "Amigo Payró" (2009, p. 102), "Querido Julito" (2009, p. 124) que indicam carinho e admiração. À medida que a correspondência se intensifica, as demonstrações de afeto vão ficando mais abertas e Onetti declara: "no me olvide y cuando quiera y pueda escríbame. Sólo la noticia de que me ha llegado carta suya alcanza para dejarme más contento" (2009, p. 37) ou "un abrazo de su amigo que lo quiere y extraña y quisiera poder estar con usted sin límite de tiempo y a solas" (2009, p. 116).

Palavras como essas discrepam totalmente da figura pública que Onetti criou para si e que os críticos repetem à exaustão: homem solitário, sem amigos, sempre deitado em uma cama bebendo e fumando. Os textos da intimidade revelam um Onetti afetivo, comunicativo muito distante de afirmações como esta:

Parece huérfano, desocupado y ausente, males que padece desde siempre, por algún defecto de naturaleza, algún fracaso interior que remonta por lo menos a la adolescencia, cuando 'ya nada tenía que ver con ninguno'. Vive incomunicado, en soledad y desamparo. (HARSS, 1969, p. 215).

Onetti escreve a Payró para pedir pareceres sobre os textos que está redigindo, discutir temas de literatura e crítica, refletir sobre a realidade das guerras, mas também para dizer o que pensa sobre família e relacionamentos, 
deixando transparecer sua sensibilidade e, às vezes, fragilidade. Quando conhece a filha de Payró diz: "su niña es la muchacha más inteligente del mundo y también de Montevideo" (2009, p. 53). Em uma carta subsequente afirma: "me entristezco cuando veo niñitas de uno a cuatro años porque me gustaría mucho tener una" (2009, p. 145). O desejo de Onetti só se concretizará dez anos depois, quando nasce sua filha Isabel María, a Litty. E depois disso, segundo os depoimentos de Dorothea Muhr, sua última esposa, o dia mais feliz da semana de Onetti era a sexta-feira, quando cuidava da filha e escrevia.

Mas a carta mais emocionada é aquela na qual Onetti descreve a separação de sua segunda esposa, María Julia:

\begin{abstract}
Unas pocas líneas, justamente ahora, después de tanto silencio, para cumplir con el deber de amistad de comunicarle que Mlle. Vibert, Mlle. Miracle, ha decidido cambiar su escritor de cuentos por un homérico narrador de viva voz. Vino, estuvo una semana conmigo, ofreció quedarse por encomiable espíritu de sacrificio y acabó por irse para siempre jamás en el ómnibus de las 8:30 de la mañana de hoy, lunes 10 de noviembre del enigmático año de 1941. No puedo decirle qué fue para mí esta semana. Tenerla a mi lado y verla ardiendo y en silencio, como una bestia enferma, de su amor por otro, ver su 'cara de tierra y sus desesperados ojos' vueltos hacia el recuerdo y la esperanza de otro hombre. Todo esto después de ocho años de milagro cotidiano, luego de haberme decidido yo a cimentar en piedra mi vida con ella, cortar el resto y hacerle un hijo (2009, p. 122).
\end{abstract}

Aqui talvez Onetti já esteja fazendo literatura, mas o fato de escrever essa carta a Payró, no dia em que é abandonado pela mulher, demonstra a confiança e a dependência dessa amizade. Na correspondência posterior, Onetti descreve sua vida de solteiro, o refúgio que encontrou em prostitutas e jovens mulheres com cara de inteligente que o admiravam ainda que estivesse barbudo e sem dinheiro (2009, p. 135). Isso porque, segundo ele, ao declarar sua profissão de escritor, despertava o interesse imediato dessas gurisas (2009, p. 132).

Seja nas declarações de afeto dirigidas a Payró ou nas confidências sobre sua vida privada, Onetti deixa transparecer nessas cartas seu lado mais frágil e sentimental, o qual contrasta com sua imagem de incomunicação e mau-humor. Documentos como esses servem para modular certas afirmações sobre o escritor uruguaio, as quais não revelam o quão complexa é a sua personalidade.

\section{Em busca da aprovação do crítico}

Além de respeito e admiração, as cartas de Onetti a Payró revelam um jovem escritor à procura do parecer do conceituado crítico. Segundo Verani:
La diferencia de edad (diez años) y de madurez cultural permiten deducir que el joven escritor se acerca al catedrático consagrado para plantearle sus criterios y proyectos, sus ideas literarias y artísticas, no en busca de orientación, sino, más bien, de autoafirmación, de valorización como escritor (2009, p. 13).

Assim, é provável que Onetti envie os manuscritos de seus contos e romances iniciais a Payró para receber a crítica de alguém influente no circuito cultural bonaerense, onde o escritor pretendia publicá-los. À carta de dez de julho de 1937, por exemplo, Onetti anexa uma peça de teatro (nunca encontrada) que havia acabado de escrever e solicita a análise de Payró: "no sé cuánto puede valer teatralmente (técnica, lenguaje, tiempo, situaciones, etc.) (2009, p. 38). E assim procede com a maioria dos textos que escrevia ou reescrevia no período: O Poço, Terra de ninguém, Tempo de abraçar, etc.

Quando a crítica de Payró era positiva, Onetti demonstrava gratidão e contentamento: “¿Qué decirle de su carta sobre mi islita, ínsula o islote [que aparece em Terra de ninguém]? Sigo creyendo que es exagerada. Pero esto no disminuyó mi gran alegría por haberle gustado tanto" (2009, p. 35). À medida que a intimidade entre os dois vai aumentando, e Payró começa a enviar críticas não tão positivas assim, Onetti lança mão dessa mesma proximidade para discordar: "me ha ofendido terriblemente su consejo de releer el libro. No debe dudar hasta ese punto de mis conocimientos idiomáticos" (2009, p. 82). De todo modo, os pareceres de Payró são em sua maioria elogiosos e sua influência é determinante nesses anos de formação do escritor.

A correspondência sugere que Onetti utilizava sua amizade com Payró para interceder junto a revistas e editoriais. Em meados de 1937, escreve uma carta desaforada a Eduardo Mallea, então diretor do suplemento literário de La Nación, solicitando a devolução dos originais enviados, já que não foram publicados. Ele escreve: "si Vd. prefiere, puede hacer entrega de esos trabajos a Julio Payró [que tinha seus artigos constantemente publicados no jornal]. Creo que ésta sería la manera más rápida y cómoda para Vd." (2009, p. 47).

Em seus períodos de dificuldades financeiras, Onetti recorria a Payró para que o indicasse a jornais ou lhe cedesse algumas das traduções que realizava: "las traducciones se aceptan de antemano; pero va sin decir que me animo con cualquier Ruy Barbosa" (2009, p. 70). Isso porque Payró traduzia, à época, textos da língua portuguesa para a espanhola; o conhecimento básico que Onetti tinha do idioma limitava seus trabalhos a autores menos adeptos ao palavrório de Ruy Barbosa.

Nas cartas, Onetti faz questão de relatar suas leituras e juízos críticos a Payró, provavelmente para não parecer 
inferior ao renomado crítico e continuar sendo aceito por ele: "leo Proust" (2009, p. 55); "me voy a leer a Faulkner y tomar mate" (2009, p. 72), "respecto al de Mallea, Historia de una pasión argentina, tomo nota y desconfío" (2009, p. 46). Aproveitando a citação, nota-se que os comentários de Onetti sobre Mallea são, em um primeiro momento, mais negativos, talvez em virtude das recusas em La Nación; porém, logo depois, Onetti muda de posição e passa a julgá-lo um dos maiores escritores argentinos, como demonstraram seus artigos para a revista Marcha. E a insólita imagem de Onetti lendo Faulkner e tomando mate pode sugerir a construção de uma poética: técnicas e modelos norte-americanos metamorfoseados para representar a sociedade platina.

Sendo assim, mais do que uma amizade, Onetti procurava em Payró um interlocutor para suas primeiras produções, um juízo crítico que lhe abriria portas na cena cultural rio-platense. No entanto, mesmo sendo dez anos mais jovem e não tendo a mesma formação intelectual de Payró, Onetti mostra-se muito seguro de si e de sua obra, sugerindo até uma arrogância em certa medida inadequada a um escritor de vinte e poucos anos sem livro publicado.

\section{Seguro de si (às vezes até demais)}

No período central de sua correspondência com Payró, entre 1937 e 1941, Onetti publica sete contos (três deles de autoria reconhecida posteriormente), uma novela e um romance. Sabe-se também que estava escrevendo Tempo de abraçar, outro romance que só foi publicado em 1974. Essa produção seria muito maior se Onetti não fosse, nessa época, um escritor de horas vagas. Os empregos (na bilheteria do estádio Centenário, em uma agência de automóveis e em jornais e revistas) tomavam parte considerável do seu tempo. Ainda assim, Onetti confiava na qualidade de sua narrativa, às vezes demasiadamente.

Em uma carta, provavelmente de 1938, ele afirma estar trabalhando nas páginas "de la actual the best of the world" (2009, p. 56) referindo-se a Terra de ninguém. Em outra diz que a quantidade de trabalho o impede de "legar a las generaciones futuras algunos Quijotes y dos o tres Hamlets" (2009, p. 104). Em uma nova carta declara: "todo lo que escribo es bueno aunque no puesto a punto por falta de tiempo para dedicarle" (2009, p. 139).

Esses comentários irônicos sobre a qualidade de sua obra se repetem em vários trechos da correspondência. Quando $O$ Poço é publicado, Onetti envia uma edição a Payró, acompanhada de uma carta que diz: "me parece mil veces más verdadera, más mía, más caliente, que todas las bellas cosas que pudiera escribir y que he escrito" (2009, p. 93). Considerando que essas belas coisas são quatro contos, ainda que analisada a ironia do comentário, é possível interpretar o valor que concede a esse primeiro livro.

Ainda que essas afirmações devam ser interpretadas com o tom de piada tão costumeiro ao Onetti inicial, a repetição da brincadeira pode indicar uma tentativa de convencer o interlocutor da qualidade de sua narrativa, garantindo assim um forte aliado para a sua publicação. Como indica Hugo Verani, "consciente del valor de su obra, posición asumida sin jactancia ni falsa modestia, aunque a veces el duendecillo de la vanidad asoma y desliza frases, a menudo como chiste o broma, o como una suerte de reto tácito y deliberado al corresponsal" (2009, p. 15).

Em uma carta de 1938, talvez Onetti deixe esse duende da vaidade se manifestar. Ele está, com menos de trinta anos, imaginando o que vai dizer aos jovens escritores quando estes vierem lhe entrevistar:

A mi provecta edad es creíble que jóvenes y no tanto me pregunten, por caminos que suponen desviados y astutos, 'cómo hay que escribir'. Como soy paciente $\mathrm{y}$ - usted recordará - muy bien educado [...] aconsejo escribir como y que salga del forro del estómago (2009, p. 78).

A confiança no valor de sua obra é uma parte não muito conhecida do caráter de Onetti. As cartas mostramno incomodado com a pouca recepção de seus textos e as dificuldades em publicá-los. Diferentemente do que costuma ser comentado em sua fortuna crítica, Onetti se preocupava em frequentar reuniões com escritores, exposições de arte e atos públicos e mostrava-se impaciente pela falta de ressonância de sua narrativa (VERANI, 2009, p. 14). Como defende Pablo Rocca, "conviene librarse de una vez por todas del mito de un Onetti incomunicable, ajeno u hostil a todo contacto" (2009, p. 32).

Dessa forma, a correspondência com Payró, além de dar um singular depoimento sobre as dificuldades do mercado editorial rio-platense, indica que aquela fé na arte que Onetti declarava não ver em seus contemporâneos é um de seus traços de escritor.

\section{Empregos e dificuldades financeiras}

Justamente porque o mercado editorial ainda incipiente não garantia o seu sustento, Onetti tinha que desempenhar outras funções para manter a si e a família. Esse dilema é relatado a Payró; em um primeiro momento, a vontade de escrever é tanta que as dificuldades sequer o incomodam: 
Este portentoso empleo comercial no ha llegado a molestarme. Es tan ridículo en tarea y en sueldo que me alcanza para reírme solo. También para sacar un crédito de 72 libros en la Editorial Ercilla y para Thalen's Windsor y etc. ¿Qué más? Escribo y Mlle. Vibert sigue pintando (2009, p. 43).

É uma pena que só tenhamos acesso às cartas de Onetti a Payró. Pelo que se pode inferir, as cartas que Payró escrevia, que Onetti não conservou, vêm cheias de acontecimentos, palestras, viagens que a posição de crítico consagrado possibilitava. Restava ao jovem Onetti o relato da vida cotidiana de um aspirante a escritor, com todos os empecilhos que essa condição pode causar: "El trabajo diario tan estúpido y el tiempo que se pierde y el esfuerzo que es necesario hacer para 'casi ningún día sin escribir', producen crisis de desaliento. Pero se escribe y se está bastante contento" (2009, p. 70).

Com o passar do tempo, no entanto, os problemas financeiros começam a incomodá-lo: "y el trabajo, que aumenta cada día porque cada día hay menos dinero y todas las economías caen sobre mi lomo" (2009, p. 96). Mesmo assim, segue escrevendo: "hay que hacer periodismo y fabricar apresuradamente novelas que puedan conmover la cuenta bancaria de algún editor yanqui" $(2009$, p. 98), reiterando as dificuldades do mercado rio-platense e tentando abrir novas possibilidades de publicação que, ao menos nesse período inicial, não acontecem.

Se analisada toda a trajetória de Onetti, não se pode dizer que chegou a viver bem financeiramente somente em função de sua literatura. Nos anos sessenta, auge de sua consagração, chegou a levar uma vida confortável, mas logo teve que voltar a colaborar em jornais e revistas, inclusive em seu período madrilenho. No entanto, ainda nos anos iniciais, teve alguns curtos períodos de aburguesamento, como ele mesmo declarou, principalmente quando era funcionário da agência Reuters: "la familia se me ha aburguesado en forma alarmante y se traslada a Carrasco. Si la peste económica me continúa, es fácil que en diciembre siga ese rumbo y veranee, también burguesamente" (2009, p. 82).

Essas "experiências burguesas", contudo, não tiraram de Onetti sua consciência de classe, acostumado ao trabalho árduo e ao estilo de vida humilde. Talvez por isso, em 1955, a correspondência com Payró é interrompida grosseiramente, segundo Onetti, por não aguentar mais suas repreensões burguesas (2009, p. 159).

O jovem Onetti, interessado nos julgamentos críticos de Payró, na sua influência no meio intelectual, é capaz de transpor a diferença de classe, afinal, sairia ganhando com isso. Já o Onetti consagrado, talvez tanto quanto Payró em 1955 , não pode continuar relevando juízos com os quais não concorda. De forma alguma estamos sugerindo que a amizade de Onetti e Payró foi mero interesse - a análise das cartas demonstra uma genuína admiração pelo crítico - entretanto, essas nuances da personalidade do escritor depõem a favor da hipótese deste trabalho: a narrativa e a biografia de Onetti são muito mais heterogêneas do que se costuma alegar.

\section{Reflexões sobre literatura e crítica}

Em uma carta de 1937, Onetti reflete sobre o papel do crítico, seja na literatura ou na pintura: "siempre he pensado que la crítica debía ser así. Tomar los elementos, las sensaciones de belleza de una obra de arte y hacer con ellas una nueva belleza" (2009, p. 37). Talvez para enaltecer o ofício de seu interlocutor, Onetti afirma ter aprendido mais com a crítica de pintura do que com a literária. Hugo Verani levou a sério a afirmação do escritor e publicou na revista Insula $\sim 750$, de junho de 2009 , o artigo Onetti y la pintura. Nesse texto, Verani apresenta o relacionamento de Onetti com Payró e Torres García que, segundo ele, levou-o a exaltar os artistas que admiravam:

\footnotetext{
No debería extrañar que Onetti, familiarizado con el arte moderno, y apoyado por Joaquín Torres García y Payró, comprendiera el legado de los pintores de fines del siglo XX. El realismo de Rousseau, Cézanne y Gauguin posee la cualidad de transponer la vida diaria, cotidiana, a un mundo imaginario que nada tiene que ver con el llamado realismo mágico, mítico. Todo pertenece al orden de lo natural, de lo reconocible e inmediato, adhesión a la realidad, ajena, sin embargo, al concepto convencional de realismo (2009, p. 27).
}

Onetti viu, então, conexões entre o que seus amigos (e esposa) pintores admiravam e a narrativa que escrevia. Embora o conceito de realismo mágico aplicado à literatura seja posterior a essa primeira fase de Onetti (o prefácio canônico de Alejo Carpentier é de 1949) é possível essa relação entre pintura e literatura já que, assim como em Rousseau, Cézanne y Gauguin, a obra de Onetti não desenvolve o realismo mágico.

Sobre Gauguin, o preferido, o escritor discorda de Elie Faure, autor de Historia del arte, a respeito de sua debilidade se comparado a Cézanne. Para ilustrar a crítica, Onetti cita o quadro Mulher com fruta, que conheceu na casa de Payró:

Yo, miope de mí, siento que ese cuadro es perfecto. Matemáticamente perfecto, si se exige el término, en dibujo y color. Y aventaja a las obras maestras de Cézanne porque, dentro de un orden severo, hay allí toda la poesía que hasta la fecha es posible poner en un cuadro $(2009$, p. 42$)$. 


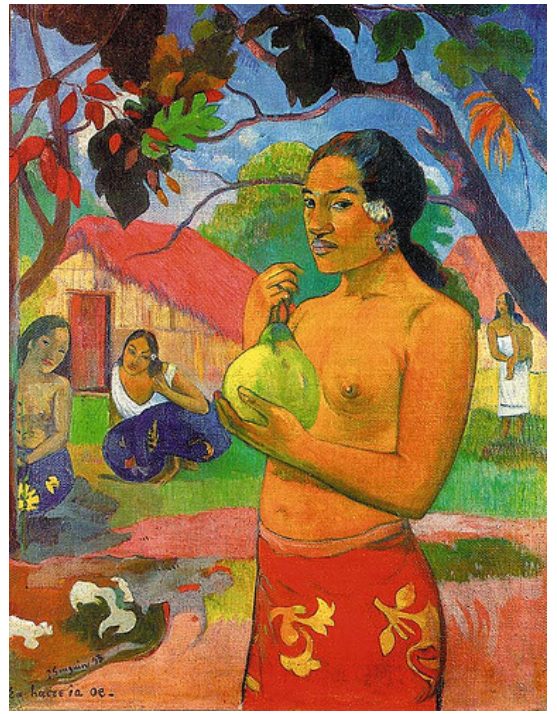

Mulher com fruta - Paul Gauguin ${ }^{1}$

Percebe-se que Onetti não domina a linguagem da crítica de arte, por isso utiliza as categorias que conhece: $\mathrm{o}$ quadro tem poesia. Mesmo assim, tenta apropriar-se dessa outra manifestação, talvez para garantir a continuidade da troca de cartas com Payró. Ainda sobre Gauguin, Onetti chega a projetar uma vida semelhante à do artista na ilha paradisíaca do Taiti. Na época de sua ascensão financeira, planeja: "quiero comprarme un terreno en una playa, lejos, hacer un rancho, conseguir veinte o treinta pesos mensuales de renta y so long. Es la sustitución de Tahití" (2009, p. 128). O projeto de Onetti não foi concretizado, no entanto, transfere seus planos aos personagens de Terra de ninguém, que também sonham com uma ilha paradisíaca.

Outro artista que é foco das análises dos correspondentes é o amigo em comum Torres García. O pintor uruguaio transladou-se muito cedo a Barcelona onde começou a definir seu traço. Depois passou por Nova York, Itália e Paris, até voltar a seu país natal, em 1934, quando inicia uma série de palestras e oficinas para jovens artistas. ${ }^{2}$ É provável que Onetti e Payró tenham se conhecido em um desses cursos, então é explicável que ambos mantenham um especial afeto pelo pintor.

Nas cartas, Onetti discute a postura de Torres na qual os artistas platinos não devem continuar imitando os europeus, devem construir uma identidade própria. Como mostram alguns textos que Onetti publicou na revista Marcha nos anos 1940, nos quais defende a formação de uma literatura nacional que não seja cópia do passado,

\footnotetext{
1 Disponível em: <http://www.flickriver.com/photos/8449304@N04/ 2551105498/>. Acesso em: 5. out. 2013.

2 Informações disponíveis no site do Museu Torres García: <http://www. torresgarcia.org.uy>. Acesso em: 5. out. 2013.
}

nem de modelos importados, pode-se entender que Onetti compartilha dessa visão de Torres quando exprime:

\begin{abstract}
No acepto ser un Achard [Marcel Achard, dramaturgo francês] platino. O Willy [William Shakespeare, segundo as notas de Verani] o un corno. O, si no hay más remedio, un tal Onetti, de Uruguay S. A. No sé si es americanismo; pero me está dando náuseas el 'escribir bien'. Pienso en alguna manera, otra, más despreocupada, más directa, semi lunfarda, si me apuran $(2009$, p. 60).
\end{abstract}

Um escritor à procura de sua poética. Percebe-se que a preocupação com a formação de um sistema autônomo dos modelos europeus é uma inquietação da época, até porque, com a destruição causada pelas guerras mundiais, havia a esperança de que a América Latina passasse a exportar conteúdos artísticos e culturais. Porém, Onetti mostra-se mais cabreiro com essa ideia do que Torres; o escritor uruguaio defendia que, enquanto a nacionalidade fosse entendida como exaltação da cor local, dificilmente a literatura dos países latino-americanos conseguiria transpor as fronteiras do continente (2009, p. 60).

Essa discussão sobre nacionalismo e americanismo ocupa a maioria das cartas destinadas a falar de Torres García. Em seu regresso a Montevidéu, o artista propunha o construtivismo como a nova arte da América, em oposição à arte figurativa associada à tradição crioula (ROCCA, 2009, p. 19). Isso vai ao encontro do projeto de Onetti para a literatura: a criação ficcional distanciada da exaltação da cor local. As ideias convergentes aproximaram os dois; Onetti afirma em um texto de Marcha:

La obra de Torres García y su personalidad actúan ya de manera invisible entre nosotros. Y más tarde o más temprano servirá de punto de arranque para una pintura sin sentimentalismo, sin literatura, sin ranchitos de paja y de terrón, sin querubines rubios, sin madres amorosas y de robustos pechos. Una pintura, simplemente (2009, p. 402).

Há outro tema, mencionado rapidamente, que merece atenção. Onetti critica a fé religiosa de Torres, colocando-a na contramão de seu ceticismo. No entanto, em quase todas as cartas Onetti faz uma referência a Deus: "Dios le dé salud y larga vida" (2009, p. 43), "Quiera el Señor que me equivoque" (2009, p. 46), "Sólo Dios sabe lo que va a resultar de ahí" (2009, p. 59), "Yo sé que Dios me lo perdonará" (2009, p. 100). É claro que podem ser apenas vícios de linguagem, mas um cético convicto não evitaria tais expressões?

Desse modo, as cartas a Payró servem para Onetti investigar o que seu interlocutor pensava sobre as polêmicas que envolviam crítica e literatura no período, 
aproveitando esse diálogo para amadurecer as posturas que exprimiria nas páginas do semanário Marcha.

\section{Ligado no mundo}

Como não poderia deixar de ser, a preocupação com o desenrolar da ditadura franquista na Espanha, a revolução soviética e os rumos da segunda guerra mundial não passaram despercebidos na correspondência de Onetti a Payró. O autor uruguaio apresenta aqui o mesmo ponto de vista que já expressara em Marcha, a condenação de políticas autoritárias:

[...] la guerra próxima parirá el fascismo o la otra cosa innombrable para buena parte del mundo [...] habrá capital, ricos y pobres, exploradores y explorados [...] yo creo que así como hemos importado el liberalismo y la democracia, los modelos de Jean Patou, los chorizos frankfurter, el psicoanálisis y Carlos Gardel y etc., importaremos también el nazismo u otra forma de la bestia. Ya hemos empezado" (2009, p. 59).

A ironia onettiana deixa transparecer que a sociedade uruguaia se formou na base de influências estrangeiras, mesmo que seja a música do vizinho Gardel. Mas deixa claro que a importação do nazismo, a besta, terá consequências irreparáveis. Afirmações como essa desmentem as afirmações sobre o caráter apolítico e descompromissado de Onetti. Nas cartas a Payró, Onetti recorrentemente mostra-se preocupado com os rumos da política em seu país e no Ocidente de forma geral.

Há outra manifestação externa que ocupa algumas linhas das cartas de Onetti: "tengo unos discos de jazz [...] los estoy escuchando en todos los momentos posibles y con mucha atención. Eso es el instinto suelto, digan lo que quieran los intelectuales jazzistas" (2009, p. 69). Assim como se encantou com aquela mulher do povo que colhia frutas no quadro de Gauguin, Onetti admira agora essa música surgida das culturas populares norteamericanas. Da mesma forma vai usar a sua arte para representar pessoas comuns no seu drama diário pela sobrevivência.

A correspondência de Juan Carlos Onetti a Julio Payró é parte fundamental dos textos iniciais do escritor, na medida em que revela posturas, preocupações e opiniões aparentemente ausentes em sua obra literária, mas importantíssimas para uma mudança na recepção desta. Juntamente com os artigos para Marcha, desponta um Onetti diferente do habitualmente retratado, o que vai possibilitar novas leituras de seus contos e romances.

Nesse sentido, a análise de documentos paraliterários, como as cartas aqui apresentadas, ilumina a obra do escritor que os redigiu e fornece novas linhas de interpretação para seus textos ficcionais. Principalmente para casos como o de Onetti, que costuma receber pareceres críticos muito homogêneos quanto a sua obra e biografia (homem solitário e frio, obra existencialista e desmarcada historicamente) a investigação baseada em cartas pessoais revela facetas que precisam vir a público para uma compreensão mais abrangente da figura do escritor.

\section{Referências}

CANDIDO, Antonio. Literatura e sociedade. Rio de Janeiro: Ouro sobre Azul, 2008.

GAUGUIN, Paul. Mulher com fruta (imagem). Disponível em: <http://www.flickriver.com/photos/8449304@N04/ 2551105498/>. Acesso em 5. out. 2013.

HARSS, Luis. Los nuestros. Buenos Aires: Sudamericana, 1969.

MUSEU Torres García (site). Disponível em: <http://www. torresgarcia.org.uy>. Acesso em: 5 out. 2013.

ONETTI, Juan Carlos. Cartas de un joven escritor: correspondencia con Julio E. Payró. Edición crítica, estudio preliminar y notas de Hugo Verani. Rosario: Beatriz Viterbo Editora; Buenos Aires: TrilceLom, 2009.

ONETTI, Juan Carlos. Obras completas I: Novelas I. Edición de Hortensia Campanella. Barcelona: Galaxia Gutenberg, 2005.

ONETTI, Juan Carlos. Obras completas II: Novelas II. Edición de Hortensia Campanella. Barcelona: Galaxia Gutenberg, 2007.

ONETTI, Juan Carlos. Obras completas III: Cuentos, artículos y miscelánea. Edición de Hortensia Campanella. Barcelona: Galaxia Gutenberg, 2009.

ROCCA, Pablo. Prólogo. In: ONETTI, Juan Carlos. Obras completas III: Cuentos, artículos y miscelánea. Edición de Hortensia Campanella. Barcelona: Galaxia Gutenberg, 2009.

VERANI, Hugo. Onetti: el ritual de la impostura. 2. ed., corregida, actualizada y ampliada. Montevideo: Trilce, 2009.

Recebido: 11 de outubro de 2013

Aprovado: 26 de novembro de 2013

Contato:kclucena@gmail.com 